with normal animals took a much deeper Nissl stain and showed a disturbance of the nucleus-plasma relation and size of the cells.

\title{
$53(463)$
}

\section{Further observations on hemolysis in cancer.}

By GeORGE W. CRILE, M.D.

This note is based on a study of fifty-two cases. Blood from three normal individuals is used for each test. With each there is a control heated to $55^{\circ} \mathrm{C}$. for ten minutes and also a salt control. A hemolytic reaction in one or more tubes is counted as a positive test. Of the cases offering a fair surgical risk, 82 per cent. showed a positive reaction; of the advanced cases 39 per cent. showed reaction. Of these all but one showed reverse hemolysis. These results conform with my former tables. The total number thus far observed is three hundred and one. In a large number of observations upon surgical patients other than those with cancer or tuberculosis, there is rarely a hemolytic reaction. In tuberculosis the reaction, when present, is always reverse. In chronic infection there is, in about ten per cent., a direct hemolysis. Among apparently normal individuals, hemolysis occurs in about two per cent.

We conclude that hemolysis occurs rarely in normal individuals, occasionally in routine surgical patients excepting those with tuberculosis and cancer. In active tuberculosis it is the rule and is always of the reverse type. In advanced cancer there is hemolysis in about two out of five patients and in these the hemolysis is usually reverse. In the operable stage of cancer among about four out of five patients direct hemolysis occurs. Hemolysis is therefore additional evidence of cancer, but in no sense specific.

$$
54 \text { (464) }
$$

On the behavior of autodermic and isodermic skin grafts in cancer.

By George W. CRILE, M.D.

I have observed in cases having growing cancers that isodermic grafts of skin from husband and from son caused a marked local reaction, characterized by excessive exudation, edema, red- 
ness and finally by the complete break-down of the grafts, while autodermic grafting later was entirely successful.

Tests in other cases were made by applying a single isograft alongside of autografts. In the cases thus far known to have at the time growing cancer, the isografts did not live. In other cases, we have not yet the final data. Histologic studies showed degeneration of the deeper cellular elements of the isografts. Nine cases were thus observed.

$$
55(465)
$$

On yeast nucleic acid.

\section{By P. A. LEVENE and W. A. JACOBS.}

[From the Department of Chemistry of the Laboratories of the Rockefeller Institute for Medical Research.]

On hydrolysis of yeast nucleic acid the following components had been maintained : adenin, guanin, cytosin, uracil, dribose and phosphoric acid. On the basis of this knowledge and on the basis of the results of the elementary composition of the acid, the composition of the yeast nucleic acid was expressed schematically in the following manner :

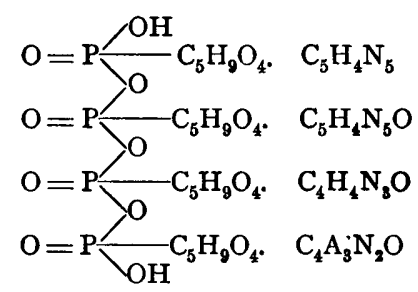

That part of this assumption which tended to give expression to the manner in which the purin bases were linked in the molecule was confirmed by the finding of two ribosides, namely, guanosin and adenosin. However, there are known some properties of the nucleic acid which cannot be well interpreted by assuming for the pyrimidin bases the same manner of union as for the purin bases.

A new substance was obtained on hydrolysis of the yeast nucleic acid of the composition of $\mathrm{C}_{5} \mathrm{H}_{9} \mathrm{O}_{4} \mathrm{C}_{4} \mathrm{H}_{4} \mathrm{~N}_{3} \mathrm{O}$. On hydrolysis the substance yields cytosin, but no ribose. It contains in its molecule one free amino group and two hydroxyls. The following crystalline derivatives of the substance were obtained : picrate 